\title{
COMO QUALIFICAR PROJETOS ACADÊMICOS DE DESIGN DE MÍDIA DIGITAL
}

\author{
Axel Sande \\ PUC-Rio \\ axel@gabinetedeartes.com.br \\ Rejane Spitz \\ PUC-Rio \\ rejane@puc-rio.br
}

Resumo: Este artigo destaca os resultados da tese de Doutorado, defendida em março de 2016, que investigou os critérios de avaliação acadêmica utilizados por professores na habilitação em Mídia Digital do curso de Graduação em Design da Pontifícia Universidade Católica do Rio de Janeiro. O período de observação da pesquisa compreendeu os dois semestres acadêmicos de 2014 em que foram analisadas as bancas finais de avaliação de projetos de conclusão de curso desenvolvidos pelos alunos da habilitação em Mídia Digital. A análise dos critérios de avaliação adotados pelo corpo docente foi fundamentada nos conceitos de síntese de projeto, linguagem da forma e experiência do usuário.

Palavras-chave: mídia digital, avaliação acadêmica, linguagem da forma, experiência do usuário.

\begin{abstract}
This paper highlights the results of a PhD research, concluded in march 2016, investigating the academic evaluation criteria used by professors in the Undergraduate Course of Digital Media Design at PUC-Rio (Pontifical Catholic University of Rio de Janeiro). The research observation period comprised the two academic semesters of 2014 with special emphasis in the final evaluation events in which the professors group analyses the conclusion course projects developed by the students of Digital Media Design. Analysis of the adopted criteria was based on the keyconcepts of project synthesis, form language and user experience.
\end{abstract}

Keywords: digital media, academic evaluation, form language, user experience. 


\section{INTRODUÇÃO}

Desde o final dos anos 1980, inúmeras áreas de atuação do design passaram a ser viabilizadas através das tecnologias computacionais. Ambientes acadêmicos dedicados às mídias digitais estão sendo concebidos e, devido às suas particularidades, adotam enfoques ainda não consolidados no campo de conhecimento do design.

No caso da habilitação em Mídia Digital da PUC-Rio, implementada em 2007 no curso de graduação em Design, seu corpo docente ainda não conta com professores graduados em design de mídia digital, já que os primeiros profissionais formados nesta habilitação graduaram-se não faz muito tempo. Isso faz com que a habilitação seja estruturada por meio de diferentes áreas de conhecimento e possibilita diferentes expectativas quanto aos resultados a alcançar nos projetos para mídias digitais. Quando confrontadas, estas diferenças de expectativa podem parecer incongruentes e tornarem-se obstáculos para a avaliação de projetos ao dissociarem os conceitos de síntese de projeto, linguagem da forma e experiência do usuário.

Este artigo baseia-se em uma tese de Doutorado recente sobre os critérios de avaliação utilizados nas bancas de conclusão de curso da habilitação em Mídia Digital da PUC-Rio. Durante as bancas finais, as avaliações tenderam ora a priorizar os aspectos formais do projeto, ora a privilegiar as possíveis experiências daqueles que venham a utilizar os dispositivos projetados.

Para a fundamentação teórica dos conceitos de síntese de projeto, linguagem da forma e experiência do usuário, a pesquisa contou com autores de diferentes áreas do conhecimento, como Roland Barthes (1981 e 2001), Mike Baxter (2008), Nigel Cross (1982 e 2012), Alain Findeli (2001), Adrian Forty (2007), Jorge Frascara (2000, 2002 e 2004), James Gibson (1979), Walter Gropius (2004), David Harvey (1993), Steven Heller (2001 e 2008), Klaus Krippendorff (1989 e 2006), Philip Meggs (1994 e 2009), Alva Noë (2004) e Edward Tufte (1983) entre outros. Quando postos em comparação, os argumentos apresentados por tais autores destacam abordagens diversas. Da mesma maneira, a avaliação dos resultados de projeto pode empregar parâmetros divergentes, ora fundamentados nas ciências exatas por um viés fundamentalmente pragmático, ora, nas ciências humanas, incorporando a subjetividade de componentes histórico-culturais. Também é possível encontrar polarizações quanto ao potencial interativo das mídias digitais que, por um lado, passam a forjar um ambiente propício à fragmentação e à ruptura de paradigmas universalistas, e por outro, parecem resgatar padrões de homogeneidade.

A metodologia, respaldada na análise categorial-temática de Laurence Bardin (1977), teve como procedimentos operacionais, as etapas de levantamento, transcrição, tabulação dos dados levantados, e, por fim, a construção de um corpus textual comparativo. Os diversos componentes que atuam como critérios de avaliação foram analisados pela combinação de técnicas qualitativas e quantitativas de pesquisa, baseadas nas falas dos professores durante as bancas finais da habilitação em Mídia Digital, para, em seguida, relacionar as falas à fundamentação teórica da tese. Seu viés exploratório garantiu a apuração de abordagens recentes e não tradicionais para o campo do design além de apontar para o desenvolvimento de proposições metodológicas de ensino/avaliação de projetos que considerem o entrelace mais efetivo dos conceitos-chave da pesquisa. 


\section{A HABILITAÇÃO EM MÍDIA DIGITAL NA GRADUAÇÃO EM DESIGN DA PUC-RIO}

Em 2007, além da implementação das habilitações em Mídia Digital e Moda, a graduação em Design da PUC-Rio passou por uma extensa revisão curricular que resultou no aumento significativo da carga horária das disciplinas de Projeto. A nova proposta de currículo passou a oferecer disciplinas de Projeto em todos os semestres das habilitações em Comunicação Visual, Projeto de Produto, Moda e Mídia Digital.

Nas quatro habilitações, as disciplinas de Projeto são divididas nos módulos Básico, Avançado e Específico. No caso da habilitação em Mídia Digital, o módulo Específico é constituído pelas disciplinas DSG1041 e DSG1042, referindo-se às fases de concepção, fundamentação e execução das propostas do trabalho de conclusão de curso. A disciplina Projeto em Design de Mídia Digital (DSG1041) contempla o reconhecimento, pelo aluno, de uma lacuna de oportunidade para o desenvolvimento de projeto e a concepção de propostas conceituais com base nas especificidades do design de mídia digital. Os alunos desenvolvem um planejamento detalhado com metas, nichos e reconhecimento de oportunidades, aliados a pesquisas teóricas, estéticas e de casos similares. Ao final da disciplina DSG1041, o aluno deverá ter incluído ao relatório da disciplina o escopo do projeto, a documentação da proposta em andamento e estudos de viabilidade técnica, com testes de simulação e desenvolvimento de protótipos.

Na disciplina Projeto Final em Design de Mídia Digital (DSG1042) são detalhados e executados os projetos de design de mídia digital. Durante o semestre de execução do projeto de conclusão do curso, o aluno finaliza a documentação, estruturação e refina o produto a ser apresentado na banca de conclusão do curso. Na primeira avaliação da disciplina DSG1042, que acontece ainda no início do semestre, são verificadas se as correções pedidas na disciplina anterior (DSG1041) foram implementadas, analisados o planejamento de metas e cronograma. Nas segunda e terceira avaliações são verificados o andamento do projeto, avaliados a documentação do produto, o relatório do projeto, e uma "versão beta" do produto em desenvolvimento. O Demo Day acontece uma semana antes da avaliação final. Nele, os alunos apresentam seus produtos finalizados que ficam disponíveis para testes de uso por professores e alunos da disciplina. Na avaliação final, que encerra a disciplina, são analisados a documentação do projeto, o produto e a apresentação final do aluno. Na apresentação são avaliados os slides, vídeos e a postura pessoal do aluno diante da banca. Durante esta última fase, com a presença de três professores do Departamento de Artes e Design da PUC-Rio, os projetos são defendidos nas bancas, como requisito parcial de conclusão da graduação em Design.

Na pesquisa da tese de Doutorado foram acompanhadas e registradas apenas as bancas finais da disciplina DSG1042, que contaram com a participação de 13 professores.

\section{OS CONCEITOS DE SÍNTESE PROJETUAL, LINGUAGEM DA FORMA E EXPERIÊNCIA DO USUÁRIO}

Os três conceitos-chave respaldaram o princípio norteador da pesquisa, que compreendeu como resultados de projeto, os elementos formais somados aos fenômenos advindos da interação entre esses elementos formais e a sociedade. Em outras palavras, além do que é "entregue" ao final do projeto, o resultado é aquilo que se obtém em retorno pela implementação do (ou pela interação com o) projeto. 
No âmbito da pesquisa, a síntese de um projeto é tanto a concepção de respostas a uma questão ou oportunidade específica, quanto os resultados formais dessas respostas, contemplando, ao mesmo tempo, os resultados formais do projeto e o processo para obtê-los. A síntese projetual deriva da combinação de diversas tomadas de decisão em concordância com os objetivos do projeto e encerra-se na manifestação daquilo que é entregue pelo designer ao cliente contratante ou à sociedade quando o projeto é concluído. A síntese é, ao mesmo tempo, o resultado, o resumo e a essência do projeto.

O conceito de síntese projetual vincula-se ao pressuposto de geração de sentido e é fundamentado pelas teorias ligadas à forma, pois seus princípios transcendem o campo da visualidade e abarcam potencialmente todos os sentidos do corpo humano. A forma, neste sentido mais amplo, representa todos os elementos perceptíveis e compreende a multiplicidade de interações permitida no contato direto com o artefato, abrangendo imagens, áudios, odores, sabores e, inclusive, as estruturas de navegação dos dispositivos interativos.

Durante as interações com os artefatos, as experiências deixam de ser algo que ocorre com as pessoas para vincularem-se aos significados percebidos pelas pessoas através dessas interações. As experiências, com base na geração de sentido, são definidas como interpretações e tornam-se também resultantes dos projetos.

Dentro de uma abordagem pela desmaterialização do design é reduzida, se não, retirada dos designers a responsabilidade de conceber as soluções formais. Com base no conceito de empoderamento do usuário, os designers passam a trabalhar em parceria com as pessoas a que o projeto é destinado, tanto nas fases de análise do problema quanto nas fases de geração e implementação das soluções. Os resultados formais do projeto deixam de ser o foco para a avaliação de eficiência no campo do design, cedendo espaço para a etapa analítica e para os benefícios obtidos na implementação do projeto. Esta abordagem compartilha a incumbência de geração dos resultados formais com os beneficiários do projeto, assinalando os enfoques na experiência do usuário e o processo de empatia. Em contrapartida, é apontada a gradativa desvalorização dos fundamentos teóricos ligados à linguagem visual.

Atualmente, o campo do design investe em aspectos historicamente pouco associados à sua atividade, assim como, questiona a relevância social de vínculos já consolidados. Posicionamentos inovadores são indispensáveis para o amadurecimento profissional dos designers contemporâneos, todavia, impõem desafios.

\section{ASPECTOS METODOLÓGICOS E GRUPOS TEMÁTICOS}

A metodologia adotada na tese, baseada na técnica de análise de conteúdo de Laurence Bardin, buscou destacar e compreender os critérios de avaliação de projetos de design para mídias digitais, relacionando tais critérios com os conceitos-chave da pesquisa.

A primeira fase de entrevistas (realizadas em outubro e novembro de 2013) teve o intuito de conhecer as quatro habilitações do curso de graduação em design da PUCRio. Os supervisores das habilitações foram entrevistados e definiram características estruturais, pedagógicas, competências e conhecimentos específicos para cada habilitação, além de apresentarem as especificidades dos trabalhos de conclusão de curso de seus respectivos alunos. 
O segundo procedimento de observação e análise foi dirigido apenas aos projetos de conclusão de curso desenvolvidos dentro da habilitação em Mídia Digital. Nesta etapa foram analisadas as bancas finais de 32 projetos de conclusão de curso.

Durante o processo de análise das falas dos professores nas bancas finais, os temas foram destacados e agrupados. Ao final das fases de levantamento e tabulação dos dados, haviam sido apontados 15 grupos temáticos utilizados pelos professores para a avaliação dos projetos de conclusão. A ordem numérica dos grupos não denota o grau de importância dos temas, mas corresponde à cronologia em que os grupos foram destacados, pelo pesquisador, durante a análise das transcrições. Os grupos temáticos são:

O grupo 1, Análise conceitual e acadêmica da pesquisa, reúne os diversos posicionamentos sobre a redação dos relatórios (ortografia, gramática etc.), a descrição dos processos de pesquisa devidamente documentados, fundamentações teóricas, citações, análises de similares e capítulos de conclusão. $O$ foco deste grupo é a pesquisa acadêmica e o relatório final é visto como documento científico.

O grupo 2, Competências do aluno, apresenta os posicionamentos sobre o desempenho do aluno durante o curso, em particular durante as disciplinas de projeto final, e sua conduta na apresentação do projeto. Este grupo foca no aluno e em sua ligação com a instituição de ensino representada pelo relacionamento com professores e colegas do curso.

O grupo 3, Documentação, reprodutibilidade e desdobramentos, diz respeito às falas sobre as possibilidades de replicar os projetos apresentados, sobre a existência e a qualidade do manual de construção do produto. O foco deste grupo é a documentação de todas as etapas do projeto, em especial de seus resultados finais.

O grupo 4, Montagem de experimentos e prototipagem, engloba os testes de experimentação e usabilidade, com diferentes tecnologias, materiais, propostas e abordagens na busca pela melhor solução. O foco deste grupo é a PRODUÇÃO de testes pelos autores dos projetos.

O grupo 5, Pesquisa de mercado, utilidade social, experiência do usuário, engloba questões sobre o público a que o projeto é destinado, o preenchimento de lacunas de oportunidade, a conexão com a sociedade, mercados produtores e consumidores, além de analisar as respostas do público a testes e protótipos. Este grupo foca nas RESPOSTAS dos testes e pesquisas para compreender o público, os usuários diretos, o mercado e a sociedade na qual o projeto pretende ser inserido.

0 grupo 6, Análise gráfica, linguagem, expressão, narrativa e comunicação visual, trata da preocupação com o diálogo entre as habilitações em Mídia digital e em Comunicação Visual, com o cuidado visual, os resultados formais e a análise gráfica, tanto na apresentação do relatório, do manual do produto, do projeto concebido e no material produzido para a defesa na banca, como em vídeos explicativos e na apresentação de slides. Este grupo foca na análise dos resultados manifestos, vistos como linguagem e comunicação.

O grupo 7, Artes, trata da relação com o universo das artes visuais, eletrônicas, cênicas, literárias etc.

O grupo 8, Inovação, pioneirismo e empreendedorismo, aborda os temas relacionados com o ineditismo do projeto, o pioneirismo no emprego de processos inovadores, tanto para a concepção quanto para a implementação dos projetos, buscando novos enfoques para a atividade do design, assim como o preenchimento de lacunas de 
oportunidade. Este grupo foca na inovação que transcende o emprego tecnológico.

O grupo 9, Tecnologia e relação homem/máquina, complementa o anterior pelos posicionamentos sobre o rigor tecnológico/técnico, a implementação tecnológica do projeto, sobre o funcionamento do artefato projetado, a ênfase em evitar a simulação de funcionamento e de navegação, o emprego de programação. O foco deste grupo é a inovação tecnológica.

O grupo 10, Interdisciplinaridade, abrangência e relevância do tema, aborda intercâmbio de disciplinas, a abrangência do projeto e a importância do tema abordado.

O grupo 11, Profissionalismo do projeto e do aluno / aplicabilidade / empregabilidade, como o próprio nome revela, foca na maturidade do projeto e sua possível inserção no mercado profissional. Vale esclarecer que, caso o critério "profissionalismo" tenha sido empregado para descrever o autor do projeto, esta foi categorizada como grupo 2 (competências do aluno).

O grupo 12, Análise sobre as habilitações do curso, aborda os comentários em torno das quatro habilitações do curso de design da PUC-Rio.

O grupo 13, Funcionamento, simulação de funcionamento do dispositivo e usabilidade, discute os benefícios de fazer o projeto funcionar em vez de apenas apresentar uma simulação do funcionamento planejado, tanto a partir da programação quanto de testes de usabilidade.

O grupo 14, Síntese como processo (escolhas) e resultados (implementação) em relação aos objetivos de projeto, trata das escolhas, das tomadas de decisão durante o processo de concepção e desenvolvimento do projeto, além de avaliar os resultados decorrentes de tais decisões.

O grupo 15, Relação com cliente, discute a complexidade de se desenvolver projetos de conclusão concebidos para clientes contratantes.

\section{CONSIDERAÇÕES FINAIS}

O design, como atividade projetual, vem conquistando gradativamente uma maior participação estratégica nos negócios e na sociedade, em grande parte, pela potencial maleabilidade das mídias digitais e por sua capacidade de mensurar resultados. Atualmente, os meios digitais permitem muito mais flexibilidade, se comparados aos modelos de produção em larga escala, característicos da modernidade. Isso tudo deveria ampliar e diversificar experimentações, ao mesmo tempo em que tornaria desnecessária a busca por linguagens universais capazes de comunicar a todos da mesma maneira. No entanto, embora a predisposição interativa dos sistemas computacionais possa ser compreendida como favorável ao fomento da pluralidade, em relação ao uso da linguagem visual, todavia, isto parece não ter ocorrido.

As abordagens científica, empreendedora e social são determinantes para a avaliação dos projetos acadêmicos na habilitação em Mídia Digital da PUC-Rio. A abordagem científica favorece a observação, o raciocínio lógico, as fases analíticas e as experimentações comprobatórias para respaldar as diversas tomadas de decisão durante o desenvolvimento de projetos. As abordagens empreendedora e profissional destacam a geração de soluções inovadoras, de possíveis impactos sociais, desdobramentos comerciais do projeto através de sua possível inserção no mundo real. As características pessoais dos alunos são percebidas como parte dos resultados dos projetos quando compreendem algo adquirido ou aprimorado pelo aluno durante 
o desenvolvimento do projeto. Neste caso, as abordagens empreendedora e profissional avaliam a seriedade, a tranquilidade, a autoconfiança e a maturidade, assim como, as capacidades de organização, de ouvir as sugestões dos professores e sua capacidade de entregar resultados. A abordagem social também impacta 0 desenvolvimento de projetos reconhecendo lacunas de oportunidade, mudanças de comportamento e melhorias sociais por meio das especificidades do design de mídia digital.

Através das falas dos professores foi percebida a importância das experimentações, necessárias para validar os resultados formais dos projetos de design, além da simplificação visual e da reprodutibilidade dos projetos serem valorizadas. As experimentações são a etapa necessária para o descarte das soluções menos eficientes dentro de um contexto real. Além disso, com base em um "fazer reflexivo" (SCHON, 2000), elas complementam a fase conceitual do projeto ao evidenciarem outras questões e incluí-las no processo de concepção de respostas. A simplificação dos elementos formais visa reduzir o esforço no acesso a uma determinada informação e fundamenta-se em valores ligados ao design moderno, em preceitos de usabilidade e de visualização de dados. As avaliações também focam na continuidade/reprodutibilidade dos projetos e relacionam-se com os resultados tanto formais quanto os gerados pela experiência na interação social. Com o foco na reprodutibilidade dos projetos, os resultados formais estão subordinados à facilitação do acesso ao conteúdo, valorizando a capacidade do projeto ser replicado, atualizado ou alterado.

Alguns critérios legitimam a avaliação dos elementos formais dos projetos a partir do uso da linguagem visual e do processo de síntese. Quando o foco está na síntese, os resultados formais são avaliados por sua capacidade de representação dos objetivos conceituais dos projetos, indicando a concepção de um conceito aliado ao processo de concretização desse mesmo conceito no projeto concluído. A palavra "estética" surge frequentemente nas falas dos professores para referir-se a uma etapa de pesquisa de referências que auxilia o aluno na definição de diretrizes formais para o projeto em andamento. No entanto, embora a pesquisa estética apareça em quase todos os relatórios finais na habilitação em Mídia Digital, a análise dos aspectos estéticos, visando a integração de padrões comportamentais ou de construções culturais, praticamente não é mencionada nas falas dos professores. Em termos dos critérios praticados nas bancas finais da habilitação em Mídia Digital, os posicionamentos pautados na linguagem visual foram, em muitos casos, próximos a estratégias restritivas originalmente vinculadas a parâmetros de produção em larga escala.

Com base nas falas dos professores e, em sintonia com a fundamentação dos preceitos de usabilidade, as avaliações dos resultados formais restringiram-se a valores universalistas da percepção visual com foco na visualização de dados. Sob esse aspecto, o enfoque dado para a linguagem visual poderia ser considerado tradicional, pois se aproxima das influências modernistas dos anos 1950. Os alunos são incentivados a recorrer a soluções visuais já consolidadas por critérios de usabilidade, tendências tipográficas e de composição gráfica em nome da eficácia perceptiva, da neutralidade e da simplificação baseada num suposto "senso comum universal". A mesma abordagem é encontrada nas teorias da percepção visual que embasam posicionamentos no campo do design da informação e parecem contemplar, até os tempos atuais, uma linguagem perceptiva comum a todos os seres humanos, em 
todos os tempos e em todos os lugares.

A fundamentação teórica da pesquisa indica que as metodologias atuais para a gestão de projeto de design são propícias ao controle e à medição dos benefícios alcançados. Todavia, a fundamentação também respalda o princípio de que projetar a experiência de outra pessoa é metodologicamente inexequível. Assim como a percepção, toda experiência seria uma ação subordinada às condições particulares daquele que a vivencia. Segundo esta premissa, o que podem ser planejados são os artifícios "geradores de experiência" (FLUSSER, 2015) mediante a interação das pessoas com os resultados perceptíveis do projeto. Estes artifícios são recursos concebidos e propagados através da percepção da forma, variando seus significados de acordo com a competência, a familiaridade e os entendimentos das pessoas na interação com os resultados formais projetados.

Com referência à habilidade dos designers de projetar os artefatos presentes na cultura material, distinguindo-os dos demais, a pesquisa conclui que o planejamento comunicacional através da forma deve contemplar a subjetividade de seus interagentes e compreender a relação indissociável entre os elementos formais perceptíveis e a geração de significados. Neste sentido, a tese sugere que os projetos sejam validados tanto pelos resultados/benefícios na interação social quanto pela análise formal desses mesmos resultados.

A capacidade dos designers de moldar as maneiras com as quais o mundo artificial se manifesta ultrapassa as funções de embelezamento, decoração ou visualização de dados. Ela alude à construção de sentidos. Para Krippendorff, fazer design "é dar sentido às coisas". A complexidade dos meios contemporâneos é administrada pela distinção entre as características relevantes para os usuários e as irrelevantes ou potencialmente prejudiciais à interação com o ambiente. Compreender a capacidade dos designers de intervir e gerar características socialmente relevantes deve tornar-se determinante para o desenvolvimento de projetos voltados às sociedades da informação.

Segundo a pesquisa, os projetos acadêmicos de design de mídia digital devem ser qualificados através das inter-relações entre os conceitos de síntese, linguagem e experiência. O campo do design deve ser definido como um ambiente de elaboração de resultados originais com o uso de conceitos familiares, "naturalizados", partindo sempre do pressuposto de que uma boa comunicação é a convergência entre novidade e reconhecimento. A compreensão dessa habilidade está presente em grande parte do conhecimento ligado à atividade do design e confirma que a experiência depende de como a forma é interpretada, assim como, que a linguagem da forma é concebida com base em experiências recorrentes.

\section{REFERÊNCIAS}

BARDIN, Laurence. Análise do conteúdo. Lisboa: Edições 70, LDA, 1977.

BARTHES, Roland. Camera Lucida: Reflections on photography. New York: Hill and Wang, 1981.

. Mitologias. 11ạ ed. Rio de Janeiro: Bertrand Brasil, 2001.

. A aventura semiológica. São Paulo: Martins Fontes, 2001b.

BAXTER, Mike. Projeto de Produto: guia prático para design de novos produtos São Paulo: Blucher, 2008. 
CROSS, Nigel. Designerly Ways of Knowing In: Design Studies: Vol 3 no 4, October 1982.

. Research in Design Thinking. P\&D Design 2012 / 10 Congresso Brasileiro de Pesquisa e Desenvolvimento em Design, São Luís, MA, 2012.

FINDELI, Alain. Rethinking Design Education for the 21st Century: Theoretical, Methodological, and Ethical Discussion. In: MIT Press Journals Winter, Vol. 17, No. 1, 2001, p. $5-17$

FLUSSER, Vilém. A arte: o belo e o agradável In: Artefilosofia: Antologias de textos estéticos / Organização: Gilson lannini, Douglas Garcia e Romero Freitas. Rio de Janeiro: Civilização Brasileira, 2015. p. 42-46.

FORTY, Adrian. Objetos de desejo: design e sociedade desde 1750. São Paulo: Cosac Naify, 2007.

FRASCARA, Jorge. Communication design: principles, methods, and practice. New York: Allworth Press, 2004.

Diseño Gráfico para la gente. Comunicaciones de masa y cambio social; Buenos Aires: Ediciones Infinito, 2000.

. People-centered design: Complexities and uncertainties In: Design and the Social Sciences: Making Connections. London. Taylor \& Francis, 2002. p. 33-39. GIBSON, James J. The Ecological Approach to Visual Perception. Hillsdale, NJ: Lawrence Erlbaum. 1979.

GROPIUS, Walter. Minha concepção da ideia de Bauhaus. In: Bauhaus: Novarquitetura. São Paulo: Perspectiva, 2004 p. 29-44.

HARVEY, David. Condição Pós-moderna: uma pesquisa sobre as origens da mudança cultural. São Paulo: Edições Loyola. 1993.

HELLER, Steven. The education of an e-designer. New York: Allworth Press, 2001. HELLER, Steven, DOOLEY, Michael. Teaching Motion Design. New York: Allworth Press, 2008.

HELLER, Steven, WOMACK, David. Becoming a digital designer: a guide to careers in Web, video, broadcast, game and animation design. Hoboken, N.J.: John Wiley \& Sons, 2008.

KRIPPENDORFF, Klaus. The semantic turn: a new foundation for design. Florida: Taylor \& Francis Group, 2006.

KRIPPENDORFF, Klaus. VÄKEVÄ, Seppo. The Language of Objects, Blueprint Vol. 52, 1989.

NOË, Alva. Action in Perception. Massachusetts: The MIT Press, 2004.

SCHON, Donald. Educando o Profissional Reflexivo: um novo design para o ensino e aprendizagem. Porto Alegre: Artes Médicas Sul, 2000.

TUFTE, Edward R. The visual display of quantitative information, Cheshire, Connecticut: Graphics Press, 1983. 